\title{
A touch of gastronomy
}

\author{
Charles Spence $^{1 *}$, Caroline Hobkinson ${ }^{4}$, Alberto Gallace ${ }^{2}$ and Betina Piqueras Fiszman ${ }^{1,3}$
}

\begin{abstract}
The last few years have seen a rapid growth of research interest in the study of the role of touch and oralsomatosensation in the experience of eating and drinking. The various ways in which the sense of touch can be used to enhance the diner's/consumer's experience in both everyday eating and drinking, as well as in the context of experiential dining, is also gaining ever more attention from professionals in a variety of disciplines. In this review, we highlight the importance that everything that we perceive via the sense of touch, from the weight of the menu to the feel of the tablecloth, tableware, cutlery, and even the food itself, has on our eating experience and food and beverage-related behaviors. Everything we feel, be it the weight, the temperature, or the texture of whatever we happen to come across while eating appears to matter. In addition, we also highlight the relevance of oral-somatosensory cues to our sensory and hedonic perception of foods. A number of examples are given to demonstrate some of the many ways in which chefs, designers, and artists are now exploiting these findings in order to change and, hopefully, to enhance the diner's eating experience in innovative ways.
\end{abstract}

Keywords: Touch, Food, Texture, Multisensory perception, Experiential dining

\section{Introduction}

With his tactile dinner parties, the famous Italian Futurist Filippo Tommaso Marinetti was perhaps the first to think creatively about the importance of touch and tactile stimulation to the act of eating, not to mention its enjoyment by diners. His suggestion was that in order to maximally stimulate the senses while dining, people should wear pajamas made of (or covered by) differently textured materials, such as cork, sponge, sandpaper, and/or felt and eat without the aid of knives and forks to enhance the tactile sensations (see [1], p. 61; [2], pp. 1-2). The movement that Marinetti founded back in 1909 with the publication of The Futurist Manifesto [3] was, in many ways, well ahead of its time. That said, the last few years have seen something of a revolution in terms of our growing understanding of the role of touch in the experience of eating and drinking and, perhaps more importantly, its exploitation in both everyday eating and drinking, as well as in the context of experiential dining.

In this article, we take a closer look at a number of the ways in which touch (including oral-somatosensation) can

\footnotetext{
* Correspondence: charles.spence@psy.ox.ac.uk

${ }^{1}$ Crossmodal Research Laboratory, Department of Experimental Psychology, South Parks Road, Oxford OX1 3UD, UK

Full list of author information is available at the end of the article
}

influence the experience of eating and drinking, and how the latest scientific insights are now starting to make their way into an increasing number of our everyday food experiences. The focus of the first part of this article will be on touch as it influences the experience of a diner in a restaurant setting. Later, we will provide an overview of the oral-somatosensory contributions to the experience of the taste/flavor of foods and beverages. These in-mouth tactile sensations affect our food and beverage experiences regardless of what it is that we happen to be eating or drinking. Furthermore, they affect us whether we realize it or not (and typically we do not). As Brillat-Savarin [4], the famous French gastronôme put it, the pleasures associated with eating and drinking constitute some of life's most enjoyable experiences. This, he thought, was especially likely to be true for the growing aging population (even more of a problem now than when he was writing). Given the importance of touch and oral-somatosensation to the experience of tasting and flavor perception (as discussed below), it is surprising that none of the many books that have been published over the years on the topic of tactile perception (for example, [5-9]) has ever mentioned the significant role that this sense plays in our experience of food and drink. Perhaps even more surprisingly, those professionals working in the fields of food science and 
gastronomy do not appear to have given this topic the thought that it most surely deserves either.

\section{On the feel of the restaurant}

The information that we receive by means of the sense of touch (not to mention the related haptic, proprioceptive, and kinesthetic cues) plays a subtle but nonetheless important role in many aspects of our eating and dining experiences (see [4,10] [11; Chapter 17]). Taking inspiration from Marinetti, there would certainly seem to be grounds for thinking that simply by enhancing the tactile stimulation delivered by the chair on which a person is sitting at a restaurant, it might actually be possible to enhance (or, at the very least, to alter) a diner's experience. Indeed, in her new book, Barb Stuckey [12] reports on a California chef who deliberately chooses throws for the back of the diners' chairs with the stated aim of delivering a richer tactile experience.

Presumably the pleasant feelings associated with dining from a table covered with a starched tablecloth (as compared to an uncovered plastic tabletop, say) might serve much the same purpose (of stimulating the diner's sense of touch). Although, of course, in the former case, or even when thinking about the role that linen napkins might play in influencing the experience of the diner, it becomes much harder to separate out any positive effects associated with the sensory properties (for example, the sight or feel) of the material of the tablecloth (or napkins) from any cultural associations that we may have with such table coverings and fine dining experiences, more generally (see [13] compare with [14]). At the restaurant Nerua, in Bilbao, Spain [15], when the service starts, the diners find themselves seated at an empty table: no cutlery, no glasses, and no plates. The waiter then brings each diner a warm napkin, as a way of transmitting tenderness and care (as its founder and chef Josean Alija states). Next, the cutlery is 'served', and depending on its temperature, the diner can infer if the plate which is going to be served next will be warm or cold.

Regarding the environment and interior décor, many top restaurants are increasingly collaborating with wellknown architects and interior designers in order to create unique dining atmospheres (see [16]) that stimulate, as much as possible, their diners' sense of touch. As Crawford [17] put it: 'surfaces made from natural materials are often preferable, as irregularity is far more sensual than clinically perfect surfaces.' However, certain restaurants or bars, involve the diners' sense of touch in a wholly different way: they incorporate new socializing interactive technologies in their counters, table-tops, or walls (such as i-Bar or i-Wall; http://www. i-bar.ch/ accessed on 25 October 2012) that produce sounds or light up as the diner touches them. In one way or another, then, it seems as though more and more importance is now being given to the experiences being delivered through the sense of touch (no matter how it is done) in the contemporary gastronomic context.

A number of bars and restaurants, such as The Ice Bar in London, also play with the environmental temperature. Such changes, as well as creating a means of differentiation from the competition in the marketplace, may also exert a subtle influence on how much people consume [18]. Elsewhere, in Paco Roncero's experimental workshop/dining space in Madrid, Spain, both the temperature and the humidity can be controlled throughout the course of the meal [19]. Furthermore, the ceramic table that people eat from is heated and can also vibrate.

\section{On the weight of the (wine) menu}

Ackerman et al. [20] reported a series of experiments in which they convincingly demonstrated that our judgments of other people (specifically, the qualities/characteristics of job candidates whose CVs we happen to be assessing) can be influenced by something as seemingly irrelevant as the weight of the clipboard on which those CVs happen to be placed. Reading about such results could certainly make one wonder whether the weight of the menu (for example, in a restaurant setting) might not also influence a diner's (or for that matter, drinker's) choice behavior, not to mention their overall impression of the feel of a restaurant or bar. Might there be, for example, a correlation between the weight of the menu and the likely price of the food/ wine that a restaurant happens to offer? And, if there were to be, have consumers/diners internalized that correlation (see [21]). One concrete question to address here in future research would, therefore, be to see whether it is possible to increase the average spend in a restaurant simply by increasing the weight of the menu.

Thus far, the tactile attributes/features of the dining experience that have been evaluated have been pretty far removed from the food and drink itself. Note that such contextual effects are likely to set up a particular expectation in the mind of the consumer that colors their experience of whatever food or drink they consumer subsequently.

\section{On the feel of the glassware}

Many consumers believe that drinks taste better when served from a heavier cup/glass than from a lighter one. Our guess is that in many cases it would be perceived by a drinker as being of higher quality as well. However, this claim is not always going to be true. The quality of bone china tea cups, for instance, is judged primarily in terms of the translucency of the china (and hence, in this case, lighter presumably equals better). While wine sometimes appears to taste better from a heavy glass, on other 
occasions, the most expensive glassware (such as the popular Riedel range of wine glasses), which can actually be surprisingly light, purportedly delivers the best taste (although see [22], for a review of the physical versus psychological effects of a wine glass on our perception of the contents). Why, one might ask should heavy glasses work under some conditions but light glasses under others? Our suggestion here would be that it is the perceived quality of the glassware that matters. In the absence of any other cue, consumers presumably use weight as a proxy for quality. However, there are occasions when the perceived quality of the glassware does not rely on the weight because the quality is otherwise apparent.

However, it is usually not only the weight of the glass that transmits that sense of quality to the contents (in the mind of the drinker), it is also the general feel of the material (that is, its quality). Krishna and Morrin [23] reported on a study in which water samples (that the participants got to taste) were perceived as significantly higher in quality when the participants were not able to touch or hold the flimsy plastic cup in which they were served than when they were. Note that in all these cases, the participants drank with the aid of a straw (so that their lips never came into contact with the container). Results such as these suggest that changes in the haptic qualities of the glass, cup, or any type of container in/on which a food is served, might have important effects on a consumer's appraisal of the quality of the product within, not to mention on their global experience. Meanwhile, in another study, Schifferstein [24] had participants evaluate either empty cups made from different materials, or the experience of drinking hot tea or a chilled soft drink from these cups. For many of the attributes that the participants were asked to assess, the results revealed that the drinking experience was related to the participants' experience of the cups. It was as if, without realizing it, the participants transferred some of their experience related to the cups themselves to their judgments of the drinks contained within.

Designers might be well advised to try to capitalize on such findings. One designer who already seems to be doing this is Ingrid Rügemer with her Frooty sensual smoothie cups. These fine bone china cups have the shape of different fruits that have apparently been designed to 'provide a new, tactile drinking experience that stimulates your senses' [25].

Another means of consuming a drink is by means of a straw (often one does this without touching the glass or cup, as for the participants in Krishna and Morrin's study just mentioned, for example [23]). After having incorporated long straws with which to drink into her experiential dinners, the conceptual culinary artist Caroline Hobkinson (see http://www.stirringwithknives. com/ accessed 27 September 2012) observed that diners tend to drink (alcoholic beverages) more rapidly when compared to drinking directly from the glass.

\section{On the weight of the wine bottle}

The increasing weight of certain wine bottles that one nowadays finds in the wine store, think of those wines that come under the header of Super-Tuscans, for example, is something that is increasingly being commented on by consumers and wine writers alike (for example, see [26]). We would argue that such manipulation in the marketplace is primarily designed to convince the undecided supermarket shopper about which bottles represent better value for money (or quality). However, that said, the weight of the wine bottle will still likely have an effect in those restaurants in which the diners have to pour the wine for themselves. (Although in this case, of course, the weight of the wine bottle is only experienced after the purchasing decision has been made.) Research from Faraday Packaging Partnership and Glass Technology Services [27] suggests that people's preference for drinks served from heavier bottles extends well beyond the world of wine: they observed that consumers also preferred vodka when it was served from a heavier bottle.

Recent research has demonstrated the significant correlation that exists between the weight of the bottle and the price that you are likely to pay for a wine. When Piqueras-Fiszman and Spence [28] recently measured the weight of all the wine bottles in a wine store in $\mathrm{Ox}$ ford (UK), they found that for every UK pound more on the ticketed price, the weight of the wine bottle increased by an average of $8 \mathrm{~g}$ (see Figure 1). The lightest bottles weighed $340 \mathrm{~g}$, as compared to $1,180 \mathrm{~g}$ for the heaviest bottle (both empty) - that is, the heaviest bottle weighed more than three times as much as the lightest bottle, all for the same $750 \mathrm{ml}$ of wine. ${ }^{\mathrm{a}}$ However, there are even heavier bottles in the




marketplace, some weighing as much as 1,500 g empty, connoting who knows what quality in the mind of the consumer! And while it is certainly true that one can make a rough guess about the weight of a bottle from its visual size alone, it is nevertheless important to note that variations in the thickness of the glass, and the depth of the punt (at the bottom of the bottle), attributes that cannot necessarily be assessed visually, can result in some bottles being surprisingly heavy when first picked up.

\section{On the feel of the plateware}

As the 'Fur-Covered Cup' [29] by Meret Oppenhein (see Figure 2) illustrates, the feel (either real or expected) of plateware against our skin (especially against sensitive regions of the body, such as the lips; [30]) can generate unpleasant sensations. Over the last couple of years, researchers have been investigating just what effect varying the weight and texture of the plateware has on people's perceptions of the food served from it.

While the visual pun of Oppenheim's work was very much about something that people would likely not want to put their lips to, psychologists, together with modernist chefs and a growing number of food and beverage producers, are currently trying to make plateware and/or packaging that, by more effectively stimulating the sense of touch, manages to enhance the diner's (or consumer's) experience of food and drink. An example of plateware that may successfully achieve this goal is Nao Tamura's silicone leaf plates, whose texture resembles that of a leaf, possibly making the eating experience more natural [31] (Figure 3).

Piqueras-Fiszman et al. [32] published what is perhaps the first study to demonstrate that eating off of heavier plateware, at least when that plateware is held by the

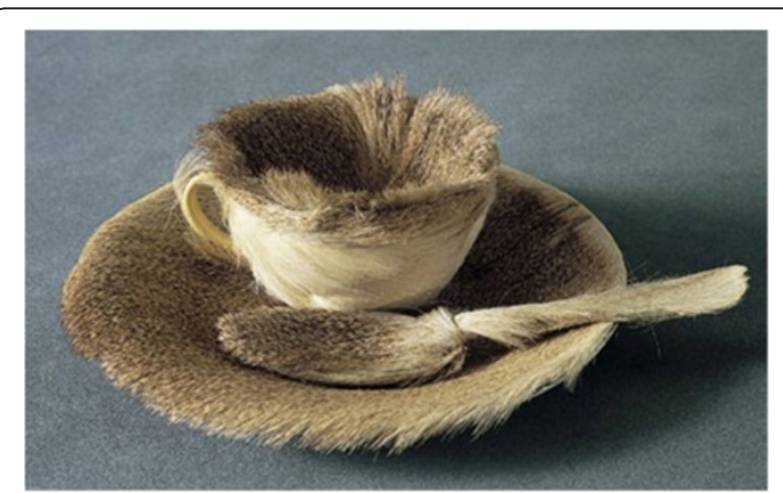

Figure 2 Meret Oppenheim's [26] Fur Covered Cup (1936). Most people find the idea of putting their lips to such a textured cup rather off-putting. Just one extreme example, then, of how the texture of the plateware may affect us. (Picture downloaded from http://www.moma.org/collection/browse_results.php? object_id=80997 on 27 September 2012).



person doing the eating, also impacts on the perceived quality of the food (in particular, on both their sensory and hedonic evaluations). Piqueras-Fiszman and her colleagues had participants rate a spoonful of yogurt served from visually-identical bowls that varied only in terms of their weight $(375 \mathrm{~g}, 675 \mathrm{~g}$, and $975 \mathrm{~g}$, respectively). The participants in this particular study sequentially held each one of the three bowls in one hand (with the order of presentation of the bowls counterbalanced across participants) while taking a spoonful of the plain yogurt from each bowl with their other hand. The participants rated each of the yogurts using a series of pencil and paper labeled line scales. The results revealed that the participants liked the yogurt served from the heavier bowl significantly more than when exactly the same yogurt was served from either of the other two lighter bowls. The participants also rated the yogurt as significantly more expensive and as significantly denser (see Figure 4).

In their subsequent research, Piqueras-Fiszman and Spence [33] have gone on to demonstrate similar effects on people's ratings of yogurt when served from either light (20 g) or heavy (95 g) plastic bowls (see also [34]). This time, the absolute variation in the weight of the plateware was much subtler, and yet the yogurt tasted from the heavier pot was still estimated as likely to be more satiating (prior to consumption), denser (once again), and as likely to be more filling, after it had been tasted (see $[35,36]) .{ }^{\text {b }}$

Now, it is not only the weight of the plateware that matters, but also its texture (especially when held in the hand, and hence felt by the diner). Suggestive evidence in this regard comes from a recent study published by Piqueras-Fiszman and Spence [37]. They reported that people rated pieces of digestive biscuit (either stale or fresh) served from a small plastic yogurt pot as tasting both crunchier and harder when the container had been coated with a rough sandpaper finish, as compared to when exactly the same food was served from a container 

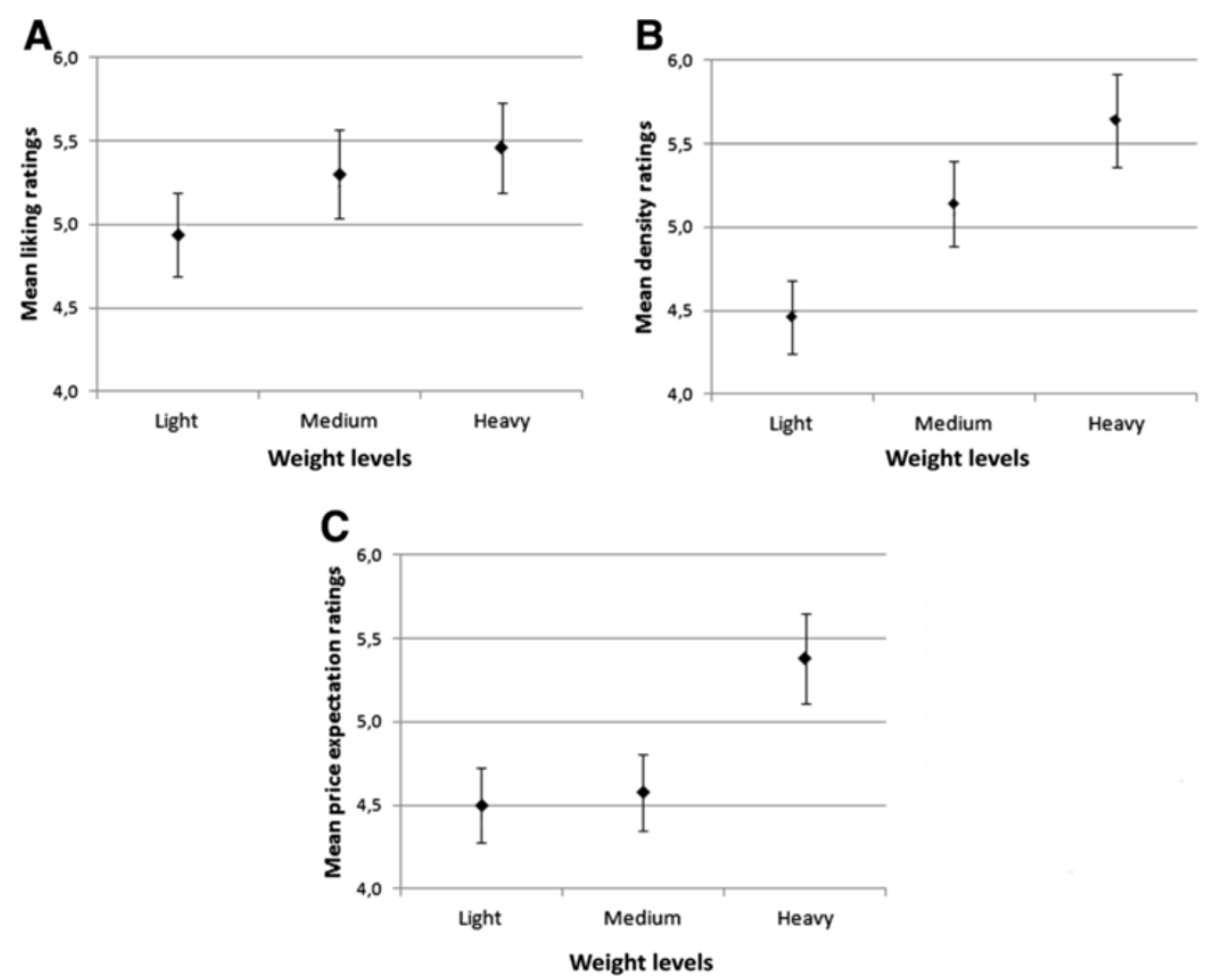

Figure 4 Results of Piqueras-Fiszman et al.'s [32] study showing how the weight of the plateware, at least when that plateware (a bowl in this study), is held in a person's hands, can enhance their perception of yogurt. [Picture redrawn from Piqueras-Fiszman et al. (2011), Figure one.]

with the usual smooth plastic feel of a yogurt pot (see Figure 5). ${ }^{\mathrm{c}}$

\section{Interim summary}

Thus, to summarize the findings reported in this section, the weight $([28,32,34])$, the texture ([37]), and possibly even the temperature (see [38], discussed below) of the plateware and glassware can all be modified in order to enhance (or, at the very least, to alter) a diner's multisensory experience of food and drink items. In contrast to the results reviewed in the previous section, the plateware and glassware are obviously much more closely related to the experience. As such, it should perhaps be less surprising that these factors have an impact on the experience of eating and drinking. While the initial results (of the feel of the restaurant, of the wine menu and so on) were accounted for in terms of touch cues setting up a particular context that colored a diner's subsequent impressions, results of the plateware on perception likely result, at least in part, from 'sensation transference' [39], by which our perception of certain sensory attributes related to the plateware may be transferred to (or come to influence) our perception/rating of the food served from that plateware. What is also worth noting here, though, is that not everyone is necessarily likely to be similarly affected by the feel of the tableware. Results originally reported by
Peck and Childers ([40,41]), and followed-up more recently by a number of other researchers (for example, $[23,42,43])$, suggest that there are stable and significant individual differences in terms of people's need for touch. Those individuals who score higher on the 'Need for touch' scale developed by Peck and Childers seem to prefer a greater degree of tactile contact than those who score lower. Particularly relevant in the context of the present chapter are findings reported by Krishna and Morrin [23]. They found that those who score higher on Peck and Childer's questionnaire tend to be influenced more by the feel of a flimsy water container than those who score lower on the scale, as mentioned above. That said, the question of why it is that some people should exhibit a much higher score on the 'Need for touch' scale than others has yet to be addressed/resolved.

\section{On the weight and feel of the cutlery}

Investigators have recently started to turn their attention to the area of cutlery design (for example, [14,34,44-46]) and, as we will see below, a number of insights from this novel area of research are already starting to appear in the context of experiential dining. In one such study, for example, Piqueras-Fiszman and Spence had participants sample vanilla yogurt using either a light or a heavy spoon (4.9 g versus $19.2 \mathrm{~g}$, respectively). The participants 




liked the yogurt sampled with the aid of the heavier spoon more than when exactly the same food was tasted using the lighter spoon. Additionally, the yogurt was rated as being of significantly higher quality (when tasted with the aid of the heavier spoon), even if the weight of the spoon itself did not affect the rated intensity of the vanilla flavor. Harrar and Spence [44] have subsequently reported similar results in a study in which they independently varied both the weight and size of the spoons that they were testing.

Elsewhere, researchers have investigated how the material properties of the cutlery affect the taste of food. For example, Piqueras-Fiszman et al. [46] recently demonstrated that eating with the aid of different spoons (coated with silver, gold, copper, stainless steel and so on) made food (in this case, cream samples to which salt, sugar, citric acid, or caffeine had been added) taste different. However, these results are unlikely to have had anything to do with touch per se, since the participants in this study were blindfolded prior to being presented with each of the spoons, and there was no discernible difference in the feel of the spoons in the hand when participants were blindfolded. Hence, in this case, it was solely the spoons' material properties (as experienced intra-orally) that affected the taste. (Perhaps if the participants had their eyes open in this study, then the impact of the different spoons on the participants' experience might have been even larger.)

Many practitioners are currently using the insights of such laboratory-based research in a real dining context.
Hobkinson (see http://www.stirringwithknives.com/ accessed on 27 September 2012) has, over the last couple of years, been hosting culinary events in which she has been experimenting by providing diners with a variety of unusual eating utensils to work with. In one such dish, for example, diners were invited to use hand-carved tree branches in order to 'spear' the foraged Chanterelles and the wild venison from the table (see Figure 6). These utensils were specifically designed to enhance the feeling of wild unaltered nature, of eating wild, gamey food.

When the House of Wolf opened in London (see http://houseofwolf.co.uk/ accessed 27 September 2012), the inaugural chef (the chef rotates every month or so), Caroline Hobkinson, created a series of courses designed to sequentially stimulate each of the diner's senses (see Figure 7 for the opening menu from the restaurant). Of particular relevance here, are the dishes on the menu that were specifically designed to engage the diner's sense of touch. These included the use of small whittled tree branches as cutlery, while another of the dishes (again designed to stimulate the diner's sense of touch more effectively) was a 'Hendrick's gin infused cucumber Granita'. This dish was to be eaten with spoons that had been treated with rose water crystals and Maldon sea salt to give them a distinctive and unusually gritty texture (see Figure 8).

\section{The tactile experience of eating}

Eating with one's hands might seem uncultured, or uncivilized in today's day and age, especially in those

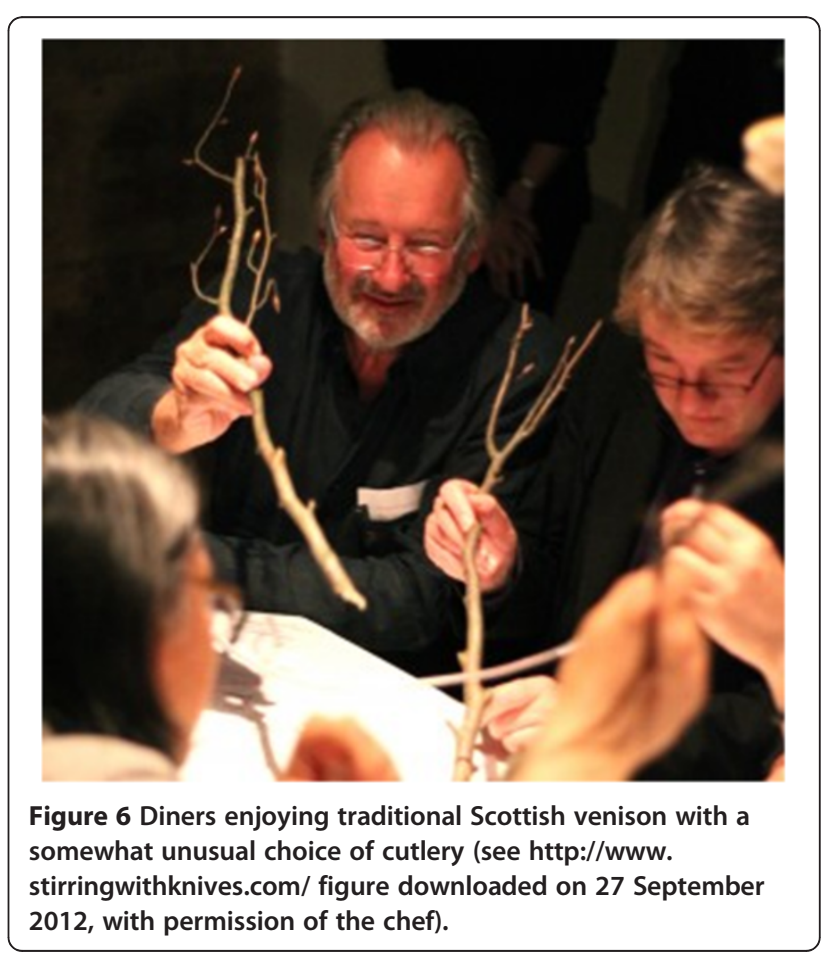


contexts where cutlery is available/provided. However, it is important to note that eating behaviors have changed over the years and now high-end meals have evolved to enable this format of eating (often referred to as 'finger food' [47], Chapter 3]). Indeed, for many eastern cultures, the practice of eating with the fingers definitely constitutes a very multisensory approach to eating, which offers a sensual, tactile experience (see [48]). As Jo Bryant, etiquette advisor at Debrett's has been quoted as saying [49], 'The influence of other cultures and new foods, such as calzone, means eating with our hands is a growing trend'. In fact, the latest version of the classic Debrett's etiquette guide has, for the first time, suggested that eating with one's hands (as suggested by the title of Zachary Pellacio's most recent cookbook [50]), now constitutes an acceptable practice, at least for certain foods, such as pizza and calzone, as long as the diners remember not to lick their fingers afterward. As fine dining becomes ever more adventurous and playful, a growing number of chefs seem to be considering course-specific alternatives to the knife and fork - that is, moving away from traditional cutlery. Some chefs, such as the Chicago-based Grant Achatz, certainly seems to invest enormous amounts of thought and planning in customizing serving vessels for each microcourse of his degustation menu ([51]). Indeed, one of Achatz's most famous dishes is a shrimp tempura skewered on a vanilla pod. Diners are instructed to tilt their heads back and take the shrimp into their mouths in one sweep.

Leaving such extravagant creations aside for a moment, the fundamental truth is that many people simply 


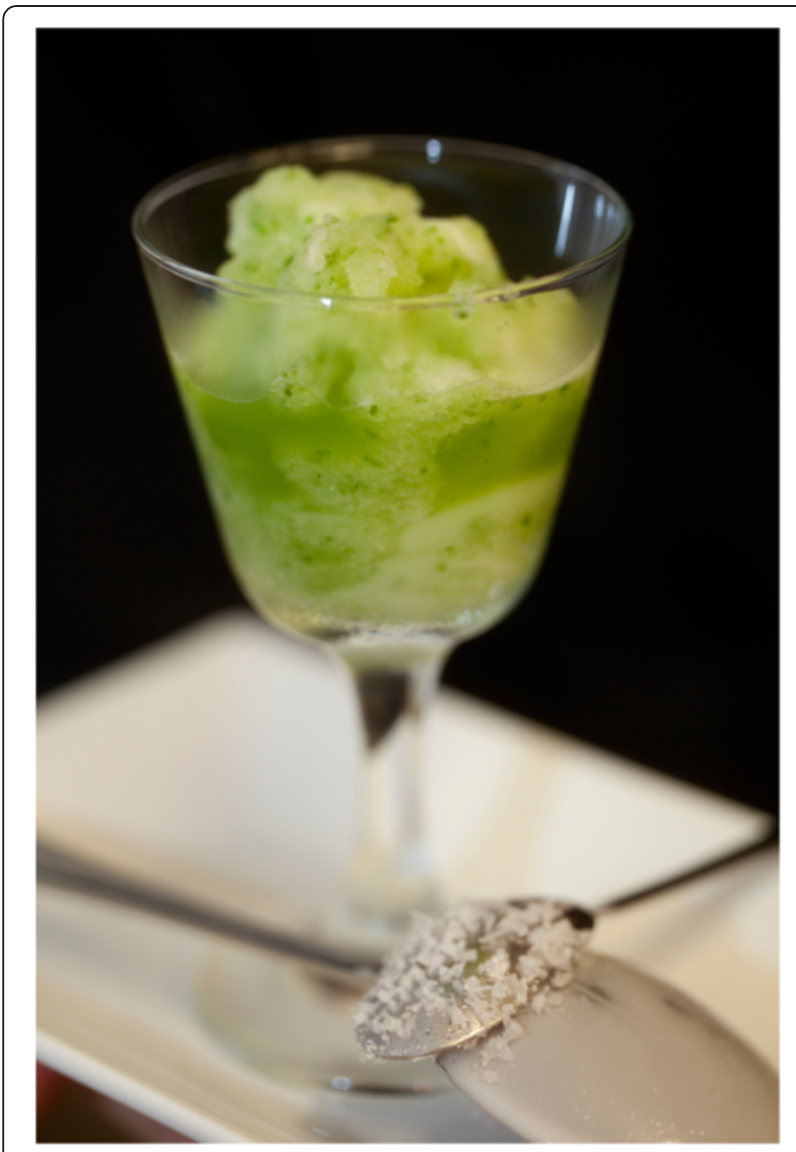

Figure 8 The textured spoons presented to diners for one of the touch courses at House of Wolf (see http://www. stirringwithknives.com/ figure downloaded on 27 September 2012, with permission of the chef).

find it more enjoyable to eat certain foods with the hands instead of using the cutlery, when provided, a hamburger being the perfect example of one of those meals (or Fish and Chips from a newspaper wrapping for The Brits [47]). In fact, it is interesting to note that a number of restaurants have recently started to appear where no cutlery is provided to the diner (for example, 'Il Giambellino' in Milan, Italy; [52]). That is, the diners are forced to eat with their hands. Some marketers have recently started to capitalize on such observations: One example comes from Kraft in Italy who used the slogan 'Se non ti lecchi le dita godi solo a metà' (If you don't lick your fingers you only half enjoy it; where in Italian 'godi' is also related to sexual enjoyment)' to advertise their 'Fonzies' crisps. Similarly, consumers often use the expression 'finger-licking good' to describe a food that they think is delicious (this was KFC's slogan, one of the best recognized, until they ditched it in 2011; http://www. dailymail.co.uk/news/article-1358784/KFC-ditches-fingerlickin-good-healthier-slogan.html, accessed on 26 October 2012).
Apart from the enjoyment that handling the food with our hands may provide to the eating experience, it is important to note that people can also evaluate a food's texture (that is, they can gain useful information) using nothing more than haptic information. In one study, for example, Michael Barnett-Cowan [53] had blindfolded participants rate the freshness/staleness and the crispness/ softness of a series of pretzels while biting into either the fresh or stale end of a pretzel. Barnett-Cowan manipulated the congruency between the tactile/haptic information provided to the participants' hand and that provided to their mouth. In half of the trials, the participants were given a half fresh-half stale pretzel (incongruent conditions); whereas in the remainder of the trials, they were given either a whole fresh or stale pretzel (the congruent condition). The results revealed that in the incongruent conditions, the stale part of the pretzel was rated as being significantly fresher and crispier in-mouth because the hands held what felt like a fresh pretzel, and vice versa when holding the stale end. Such results suggest that the perceived texture of food in-mouth can be altered simply by changing the haptic information provided to the consumer's hands (no matter whether those textural cues are delivered by the food being held in the hand or by the cutlery or plateware if that is held instead).

Note how, in the preceding sections, we have steadily moved from looking at the impact of the more peripheral aspects of touch (for example, the weight of the wine menu, the feel of the table cloth) through to the feel of those items that are more closely associated with the act of eating and drinking itself (for example, the feel of the plateware, glassware, and cutlery). In the next section, we will take a look at the more perceptual multisensory interactions taking place in mouth.

\section{Mouth-feel and the oral-somatosensory aspects of food and drink}

It turns out that oral-somatosensation plays a crucial role in many aspects of our multisensory perception of food/flavor. The tactile stimulation we receive in-mouth informs us about everything from the temperature of a food through to its texture (for example, [54-58]). Bourne ([59], p. 259) has defined food texture as: 'the response of the tactile senses to physical stimuli that result from contact between some part of the body and the food'. More recently, other researchers have been tempted to include a contribution from the other senses, such as vision, hearing, olfaction, and kinesthesia in their definitions (for example, [54] see also [53]). In terms of typical descriptions of oral texture, one might think of whether a foodstuff feels sticky, slippery, gritty and so on in the mouth.

When it comes to the tactile experiences associated with the consumption of food and drink, they are obviously 
important, although they typically fall behind taste and smell in people's ratings (especially if the opinions of those working in the food industry are anything to go by). That said, according to the results of a survey of 140 people working in various capacities in the area of food/chemical senses, temperature and texture came out ahead of color, appearance, and sound in terms of people's rankings of the importance of various sensory cues to the perception of flavor ([60]). While oral-somatosensory cues do not obviously fall under official definitions of flavor, ${ }^{\mathrm{d}}$ they are nevertheless increasingly coming to be recognized for the integral role that they play in our experience of food and drink. Indeed, some talk of touch as the forgotten flavor sense.

\section{The multisensory aspects of texture}

It is, however, not always so easy to ascertain exactly which sense is actually doing the work in terms of giving rise to specific aspects of our multisensory experience of food and drink (see [61]). For example, take attributes such as carbonation, fattiness, and astringency. While intuitively many people assume that the experience of carbonation in mouth is attributable to the feel of the bubbles bursting in the oral cavity, it turns out that carbonation is as much a result of the stimulation of the sour taste receptors on the tongue [62]. Meanwhile, most of us would say that the perception of fattiness in a food or drink is an oral-somatosensory textural attribute. However, it turns out that our experience of this food attribute does not come just from the oral-somatosensory texture/consistency of a foodstuff in the mouth: olfactory and gustatory cues are also important (for example, [63]). Indeed, a number of researchers have recently started to suggest that one of the basic tastes, that is, along with sweet, sour, salty, bitter, and umami, may be the taste of certain fatty acids (for example, [64]). Astringency too, as in an overstewed cup of tea or in a tannic young red wine (that has been fermenting in, for example, new oak barrels), is actually a tactile sensation, although many think of it as part of the taste/flavor of a beverage ([65]).

The oral-somatosensory attributes of food also give rise to what food science researchers often refer to as 'mouthfeel' (for example, [66-71]). This is the term used to describe the feeling that we have in our mouths on, and after, eating a certain food or drink. Olive oil, for example, may give rise to an oily mouth-coating, while foods containing menthol may well give rise to a cool mouthfeel. Jowitt ([72] p. 356) has defined mouthfeel as: 'those textural attributes of a food or beverage responsible for producing characteristic tactile sensations on the surfaces of the oral cavity.' Typical mouthfeel characterisics, then, include sticky, astringent, stinging, oily and so on.

The oral texture (in particular, the viscosity) of food and drink turns out to exert a significant influence on our multisensory perception of flavor (for example, $[63,73,74])$. While the results of early studies in this area (for example, [75]) often led to the suggestion that increased viscosity in a foodstuff impaired the perception of taste, it has, for many years, been difficult to disentangle whether such effects had a physicochemical, as opposed to a neurophysiological, origin (since increased viscosity is likely to reduce volatility at the food-air interface; see [76]). However, the technological advances that have been seen in the field of food science research over the last 5 to 10 years or so now mean that it is possible to isolate (and thus to demonstrate) the genuinely psychological nature (of at least a part) of this crossmodal effect (for example, [63,77]).

In one study, for example, Bult et al. [63] presented participants with a creamy odor using a computercontrolled olfactometer. The olfactory stimulus was either presented orthonasally or retronasally. At the same time, milk-like foods with different viscosities were delivered to the participant's mouth. The participants had to rate the thickness and creaminess of the resulting experience as well as the intensity of the overall flavor. Crucially, the participants' ratings of the intensity of the flavor decreased as the viscosity of the liquid increased, regardless of how the odor was presented (that is, orthonasally or retronasally). Given the independent control of texture and odor delivery in this study, these results therefore highlight the importance of texture (mouthfeel) to multisensory flavor perception in humans. Finally, Bult et al.'s results also suggest that the presence of a retronasal odor can alter the perceived thickness of a foodstuff in the mouth (see also $[78,79]$ ).

The tactile stimulation of the oral cavity is also very important for another reason: it turns out that where we localize a tastant follows the location of a tactile stimulus drawn across the tongue and not the point where the taste stimulus itself happens to have been transduced on the receptor surface ([80-82]; although see also [83]). The same may also be true for olfactants [84]. This phenomenon can be thought of as a kind of flavor-based ventriloquism illusion (for example, [85]). Thus, the fact that people localize the flavor of food to their mouth, despite the fact that the majority of the information concerning the flavor comes from their nose (that is, from olfaction) is likely attributable in large part to the tactile stimulation that they experience in their oral cavity while eating $[81,86,87]$.

Another kind of crossmodal interaction involving oralsomatosensation occurs between temperature and taste. Roughly a third to a half of the population experience what is known as the 'thermal-taste' illusion $[88,89]$. This term refers to an effect that was first documented by Barry Green and his colleagues. They found that 
simply by raising or lowering the temperature at various points on a person's tongue, they were able to elicit sensations of sweet, sour, salty and bitter - that is, the four main basic tastes [89].

In terms of the underlying neuroscience, oralsomatosensory information regarding the food or liquid in the mouth is transferred to the brain by means of the trigeminal nerve, which projects directly to the primary somatic sensory cortex [90]. This projection carries information concerning touch, texture (mouthfeel), temperature, and proprioception (not to mention nociception or oral pain, and chemical irritation) from the relevant receptors in the mouth. The results of neuroimaging studies suggest that the oral texture of a foodstuff appears to be represented in the orbitofrontal cortex as well as in several other brain areas [91,92]. The texture of fatty foods also appears to light up the cingulate cortex (see [93]). Indeed, it may have been important, evolutionarily-speaking, for our ancestors to have detected the textures of fatty foods, since they would normally have constituted a dense source of energy.

\section{The hedonics of oral texture}

It is worth noting how many of our food likes and dislikes are also dependent on the oral-somatosensory texture of particular foodstuffs (for example, [94]; see also [95]). As John Prescott ([94], pp. 25-26) points out: 'Other less obvious tactile sensations are also important in food acceptability. In particular, problems with texture are a common reason for rejecting foods'. He continues: 'The oyster is a pre-eminent example of the role that texture often plays as a reason for rejection of a food'. That said, it should be noted that a food's textural properties can also constitute a key part of what we find so pleasing (addictive) about certain other foods. Indeed, advertisements for mass-marketed red wines often make reference to mouthfeel: Take a recent print ad for Blossom Hill Winemaker's Reserve Merlot 'velvety, soft and has impeccable taste'. A number of researchers have argued that is part of the appeal of chocolate, one of the few foods to melt at mouth temperature (see [12]). Texture, then, plays a crucial role in determining our perception of a food's quality, its acceptability, and eventually our food and beverage preferences (for example, [96,97]). In addition, many chefs consider texture as a major element in their creations, searching for the diners' expression of surprise (for instance, by giving a mousse the appearance of a rock, or by giving a crunchy texture format to a food that is often consumed soft, and so on). Texture contrast is also something that many chefs work with (for example, [12] pp. 93-95), and that consumers are known to value in a food/dish [98].
One dramatic way in which to make a diner focus on the texture of the food is by removing any color cues from the dish, letting the diner discover the flavor of the foods via their texture, perceived through their hands and mouth (one might also consider that dining in dark restaurants achieves a similar goal by a slightly different means; see [99]). Relevant in this regard are the 'White funeral' meals organized by chef-artist Marije Vogelzang. They consist entirely of white food and specially designed white crockery [100], which enable one to focus on the visual, tactile, and oral texture of the foods served (see Figure 9).

\section{The sound of texture}

Our perception of a food's texture can also be perceived and modulated by the sounds that the food makes during the breakdown of its structure. Several experiments have demonstrated that food-eating sounds can make a significant contribution to our perception of crispness and freshness in foods such as crisps (potato chips), biscuits, breakfast cereals, and vegetables [101-103]. For example, the participants in one study by Zampini and Spence had to bite into a large number of potato chips (around 180 in total) and rate each one on its perceived crispness and freshness. The crisp-biting sounds were picked up by a microphone, modified, and then immediately played back over headphones. Importantly, the crisps were rated as tasting significantly crisper (and fresher) if the overall sound level was increased, or if just the high frequency components of the crisp biting sounds were boosted. Furthermore, subsequent research has now shown that people's perceptions of the crispness of potato chips can also be modified, albeit more subtly, by changing the sound of the packaging that people hold - potato chips are rated as tasting slightly, but significantly, crisper

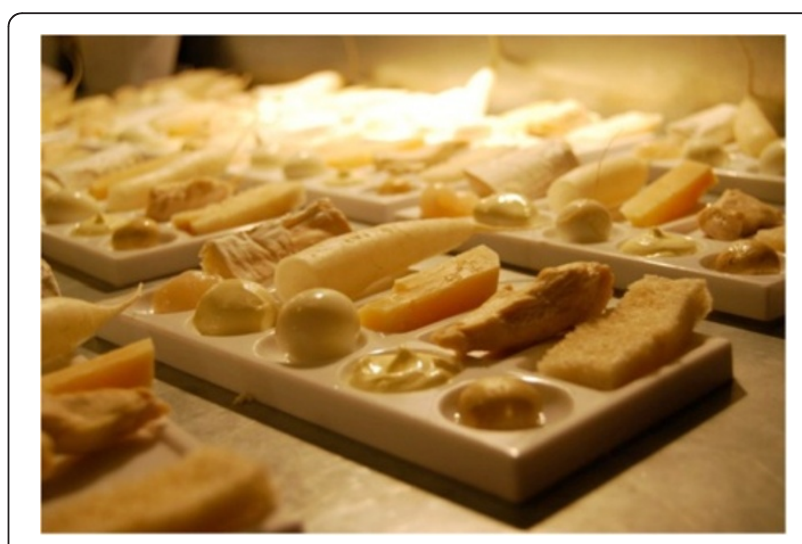

Figure 9 Detail of Marije Vogelzang's White funeral meal (see [100]; figure downloaded from www.marijevogelzang.nl on 19 October 2012, with permission of the artist). 
if the sound of a noisy crisp packet rattling is played in the background [104]. Meanwhile, elsewhere, researchers have shown that the perception of carbonation in a beverage served in a cup can also be modulated by what a person hears [105]. Thus, such results demonstrate that more of our perception of the oral texture of foods in the mouth actually depends on the sounds that we hear while eating and drinking than many of us probably realize (see [106], for a review).

\section{Social touch in the restaurant: the Midas touch}

The social (or interpersonal; [107]) aspects of touch are also important in the context of the restaurant or bar. In what is perhaps the earliest study in this area, Crusco and Wetzel [108] examined the effects of two types of social touch in the setting of a restaurant. The waitresses in this particular study were instructed to touch customers briefly as they were returning their change after they had received the bill. The researchers then compared tipping behavior under three different conditions: when the diner was touched on the hand by the waitress, when they were touched on the shoulder, and when the waitress did not touch the diner at all (the control condition). The results revealed that both male and female customers tipped significantly more after having been touched in both of the touching conditions than in the no touch condition. Subsequently, Stephen and Zweigenhaft [109] replicated this basic phenomenon, showing that touching female diners led to a $4 \%$ increase in the tips received, as compared to touching male diners, or not touching anyone at all [see also [110]. Meanwhile, researchers have also demonstrated that drinkers tend to consume more food if touched by a waitress [111]. In one study, those people drinking in pairs consumed significantly more after having been touched by the waitress; while in another study, diners were more likely to agree to a suggestion made by a waiter or a waitress after tactile contact (around $60 \%$ of times they were touched, they ordered the dish that had been suggested to them; [112]).

Of course, here it is worth mentioning that this kind of manipulation might be more acceptable to people in certain countries than others, or to certain age groups more than to others. For instance, the beneficial effects of social touch on dining were nicely demonstrated by Eaton, Mitchell-Bonair, and Friedmann [113]. They found that when the service staff who were caring for elderly people combined their verbal encouragement to eat with tactile contact, they consumed significantly more calories and protein. What is more, these positive effects on eating behavior lasted for up to five days after the tactile contact. However, we believe that how interpersonal touch affects an individual's behavior may well depend on their personal traits too (see also [114]).

\section{On the future of touch at the restaurant}

Another trend that is popular currently relates not to the enhancement of specific sensory cues (for example, through the cutlery, as mentioned before) but to their very removal. What about removing the sense of touch? One example of this comes from a most memorable experience when dining at Heston Blumenthal's The Fat Duck restaurant nearly a decade ago. For one of the courses on the tasting menu, the waiter/waitress arrived at the table, and instructed the diner to open his/her mouth and would then proceed to insert a spoonful of the latest molecular gastronomy creation (lime gelee in this case) into the diner's mouth. Restaurants like Madeleines Madteater, in Denmark, in some situations remove the plate instead, serving the food directly into the mouth of the diner with a spoon or a cannula, which are often used a as knives and forks [115]. Note that by so doing, many of the tactile/haptic elements normally associated with eating, such as the holding and wielding of cutlery, are removed. Another much more recent example of eating without the aid of cutlery comes from one of the meals organized by Caroline Hobkinson. In one dish/experience, morsels of food were tied to virtually invisible fishing wire and suspended from helium balloons that nestled under the ceiling; what is more, even the bread was also hanging from the ceiling with strings. The diners/guests entered a dark room, one in which the food is only sparingly lit, and hence it appears to be floating in mid-air (see Figure 10). The diners were then encouraged to eat the food using nothing more than their mouths to 'catch' a bite.

While the use of incongruity between the appearance of foods (and beverages) and their flavor or aroma has currently spread out among chefs as a resourceful tool to give rise to deliver surprise (see [116], for a review), it seems likely that more sensory incongruity involving specifically the oral-somatosensory attributes of the food will be found in those cases where the sight of the dish sets up sensory expectations that are incongruent with the experienced oral-somatosensory attributes of the dish. Here, one can think about the 'Hot and iced tea' dish served at The Fat Duck. The dish looks suspiciously like a normal cup of tea (see Figure 11), but actually, half of its content are warm/hot, and the rest, cold.

One technological development that is particularly fascinating in terms of the future of gastronomy involves the Virtual Straw $([117,118])$. This device recreates many of the sensations that you would normally expect to be associated with sucking a liquidized food up through a straw. The researchers concerned have managed to do this simply by generating the appropriate sounds and tactile vibrations in the straw whenever a person sucks while the straw is placed over a picture of a particular food. No food is actually delivered, but the illusion is nevertheless still a powerful one. We believe that the future will see far more 


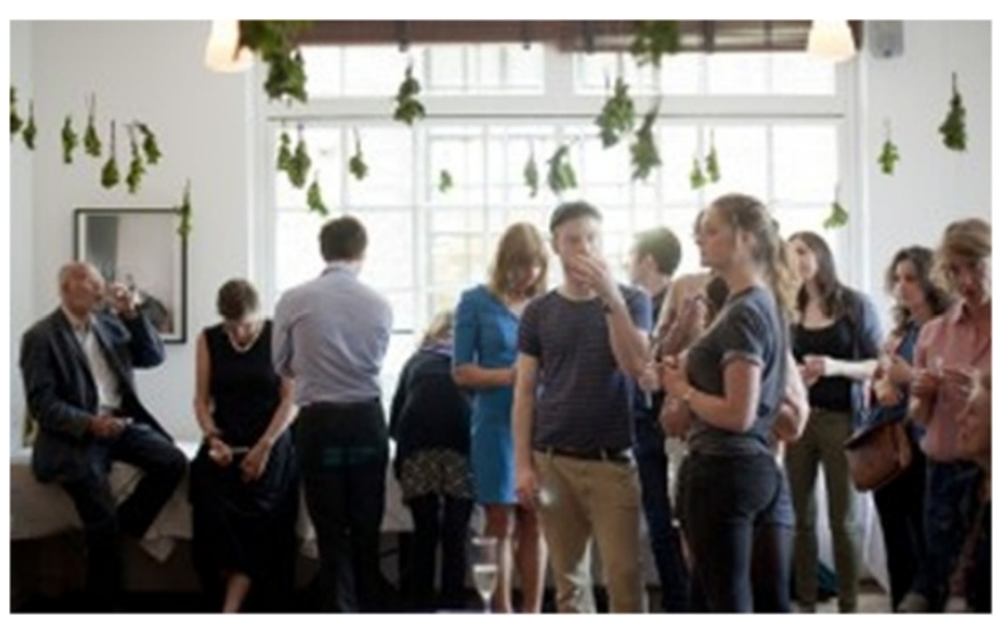

Figure 10 Eating without the aid of knives and forks in one of Caroline Hobkinson's culinary installations (see http://www. stirringwithknives.com/; figure downloaded on 27 September 2012, with permission of the chef).

examples of the latest in technology being used to enhance (or at the very least to alter) the dining experience. Furthermore, technology also allows the chef to 'break the rules' and bring fun and levity to eating experiences $[119,120]$. Even nowadays we can start seeing some examples suggested by Philips Design in its latest design probe. Through a new range of plateware concepts, they have explored how the integration of light, conductive printing, selective fragrance diffusion, micro-vibration and the integration of other sensory stimuli might affect the eating experience [121].

Technology may also be used in plateware or the utensils to modify eating behaviors. For instance, in order to remind people to eat more slowly, Toet et al. [122]

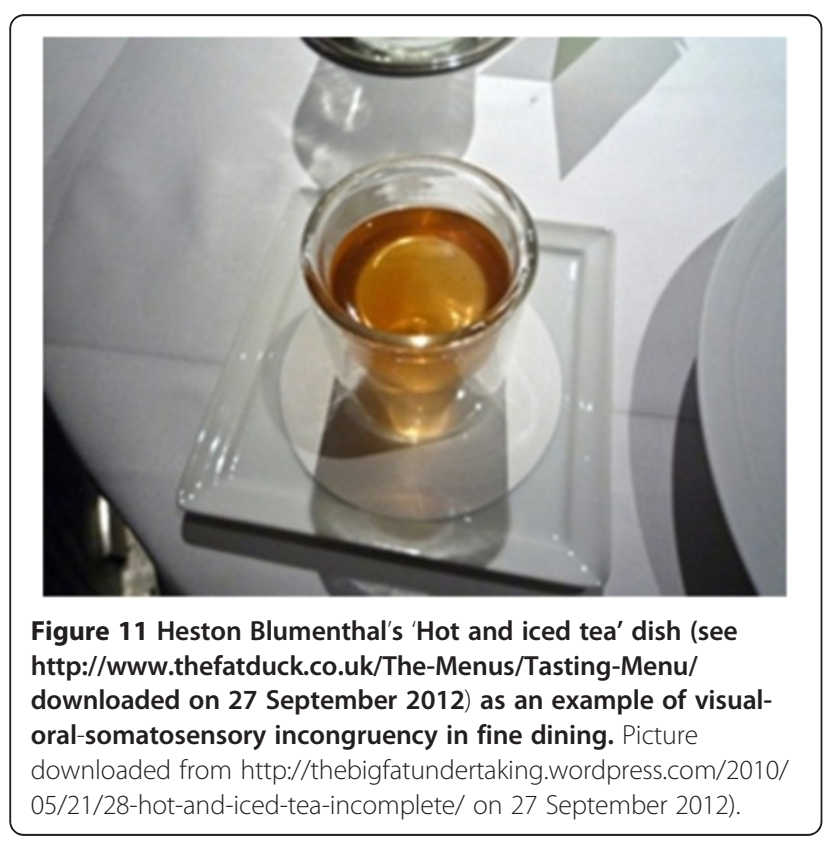

created 'vibrating cutlery'. This most tactile of cutlery was designed to detect rapid movements of the cutlery by the diner and then to vibrate briefly in order to encourage the diner to slow down. Furthermore, in contrast to molecular gastronomy, where all the new technology tends to be sited in the kitchens/research laboratories, we believe the future will see an increasing move toward technology being present at the front of house when the diner consumes a particular dish [123].

\section{Review and conclusions}

While a majority of ordinary consumers may not be especially conscious of the contribution that the sense of touch (nor, for that matter, haptics, proprioception, or kinesthesis) makes when it comes to enjoying a good meal/drink, the research outlined here has hopefully convinced the reader of just how important all of the various tactile/haptic sensations that accompany the consumption of food and drink are (and potentially will be in the future) to our overall enjoyment. While the Italian Futurist, F. T. Marinetti [3] was certainly way ahead of his time, the last few years have seen the emergence of a body of research documenting some of the many ways in which touch contributes to, and, more importantly, can enhance the consumption experience, be it in a restaurant or some other environment. What is particularly exciting for the psychologist/cognitive neuroscientist interested in the sense of touch is that artists, chefs, not to mention cutlery and plateware manufacturers and designers, are now starting to take such scientific insights on board in the offerings they present to their diners. This fact allows great opportunities for collaboration and experimentation, and even for the blurring of the limits between one field and the other. That said, it is worth remembering, in closing, that the various cases in which touch has been 
shown to influence the experience of food and drink in this article likely have a number of different explanations: certain of the effects, for example, in the section on oralsomatosensation, are likely perceptual in nature (that is, they likely result from the rules of multisensory integration). Others, meanwhile, likely have a more decisional origin. It will be the job/challenge for future research (especially for the scientists interested in this area), then, to try to ascertain the most appropriate explanation for any given effect of touch at the dinner table.

\section{Endnotes}

${ }^{a}$ Wine bottles constitute an especially interesting class of object to study in this regard since the majority of bottles contain the same amount (and hence weight) of wine. It may, of course, turn out to be for this very reason, that the manipulation of the weight of the packaging is more salient in this sector of the marketplace than elsewhere.

${ }^{\mathrm{b}} \mathrm{Such}$ results obviously raise some concerns for companies when it comes to thinking about the consequences on product perception of recent moves toward lightweighting (for example, see $[34,124]$ ).

'It should, however, be noted here that while the feel of the container influences participants' perceptions of a dry food product, it had no effect on people's ratings of yogurt. Further research will, therefore, be needed to understand the limiting conditions on this particular crossmodal effect.

${ }^{\mathrm{d}}$ The International Standards Organization (see $\left.[125,126]\right)$ defines flavor as: 'Complex combination of the olfactory, gustatory and trigeminal sensations perceived during tasting. The flavour may be influenced by tactile, thermal, painful and/or kinaesthetic effects'.

\section{Competing interests}

The authors declare that they have no competing interests.

\section{Authors' contributions}

All authors contributed to the writing of this article, and all read and approved the final manuscript.

\section{Author details}

${ }^{1}$ Crossmodal Research Laboratory, Department of Experimental Psychology, South Parks Road, Oxford OX1 3UD, UK. '2Department of Psychology, Università di Milano-Bicocca, Milan, Italy. ${ }^{3}$ Department of Engineering Projects, Universitat Politècnica de València, Valencia, Spain. ${ }^{4}$ Stirring with Knives, 54 Highbury Hill, London N5 1AP, England.

Received: 13 November 2012 Accepted: 16 January 2013

Published: 19 February 2013

\section{References}

1. David E: Italian Food. 3rd edition. London; 1987.

2. Harrison J: Synaesthesia: The Strangest Thing. Oxford: Oxford University Press; 2001.

3. Marinetti FT, Colombo L: LaCcucina Futurista: Un Pranzo che Evitò un Suicidio [The Futurist Kitchen: A Meal that Prevented Suicide]. Milan: Christian Marinotti Edizioni; 1930/1998.
4. Brillat-Savarin JA: Physiologie du Goût [The Philosopher in the Kitchen / The Physiology of Taste]; 1835. Translated by A. Lalauze: A Handbook of Gastronomy. London: Nimmo \& Bain; 1884

5. Field T: Touch. Cambridge, MA: MIT Press; 2001

6. Gordon G: Active Touch: The Mechanism of Recognition of Objects by Manipulation: A Multidisciplinary Approach. Oxford: Pergamon Press; 1978.

7. Hertenstein M, Weiss S: The Handbook of Touch. Berlin: Springer; 2011.

8. Katz D: The World of Touch (translated by L. E. Krueger). Hillsdale, NJ: Erlbaum; $1925 / 1989$.

9. Kensalo DR: The Skin Senses. Springfield, IL: Charles C. Thomas; 1968

10. Lieberman DE: The Evolution of the Human Head. Cambridge, MA: Harvard University Press; 2011.

11. Shepherd GM: Neurogastronomy: How the Brain Creates Flavor and Why it Matters. New York: Columbia University Press; 2012

12. Stuckey B: Taste What You're Missing: The Passionate Eater's Guide to Why Good Food Tastes Good. London: Free Press; 2012.

13. Anderson AT: Table settings: the pleasures of well-situated eating. In Eating Architecture. Edited by Horwitz J, Singley P. Cambridge, MA: MIT Press; 2004:247-258.

14. Piqueras-Fiszman B, Spence C: Do the material properties of cutlery affect the perception of the food you eat? An exploratory study. J Sens Stud 2011, 26:358-362.

15. Nerua restaurant. http://www nerua.com

16. Horwitz J, Singley P: Eating Architecture. Cambridge, MA: MIT Press; 2004.

17. Crawford I: Sensual Home: Liberate Your Senses and Change Your Life. London: Quadrille Publishing Ltd; 1997.

18. Brobeck JR: Food intake as a mechanism of temperature regulation. Yale J Biol Med 1948, 20:545-552.

19. Jakubik A, The Workshop of Paco Roncero: Trendland: Fashion Blog \& Trend Magazine. 2012. http://trendland.com/the-workshop-of-paco-roncero/.

20. Ackerman JM, Nocera CC, Bargh JA: Incidental haptic sensations influence social judgments and decisions. Science 2010, 328:1712-1715.

21. Spence C: Crossmodal correspondences: a tutorial review. Atten Percept Psychophys 2011, 73:971-995.

22. Spence C: Crystal clear or gobbletigook? World of Fine Wine 2011, 33:96-101.

23. Krishna A, Morrin M: Does touch affect taste? the perceptual transfer of product container haptic cues. J Consumer Res 2008, 34:807-818.

24. Schifferstein HNJ: The drinking experience: cup or content? Food Qual Prefer 2009, 20:268-276.

25. Ingrid Ruegemer: http://www.ingridruegemer.com.

26. Goldstein R, Herschkowitsch A: The Wine Trials 2010. Austin: Fearless Critic Media; 2010.

27. Faraday Packaging Partnership \& Glass Technology Services: Container lite. Light-weight glass containers - The route to effective waste minimisation. Final Report. http://www.glass-ts.com/Consultancy/ ConsultancyPDFs/ContainerLite_Lightweight__WRAP_TZ969_-_2006_pdf.

28. Piqueras-Fiszman $B$, Spence $C$ : The weight of the bottle as a possible extrinsic cue with which to estimate the price (and quality) of the wine? Observed correlations. Food Qual Prefer 2012, 25:41-45.

29. Oppenheim M: Object (Le Dejeuner en fourrure). J Amer Psychoanal Assn 1936, 44S:22.

30. Weinstein S: Intensive and extensive aspects of tactile sensitivity as a function of body part, sex, and laterality. In The Skin Senses. Edited by Kenshalo DR. Springfield, IL: Thomas; 1968:195-222.

31. Nao Tamura Seasons. http://naotamura.com/projects/seasons-milanosalone-covo.

32. Piqueras-Fiszman B, Harrar $\vee$, Alcaide J, Spence C: Does the weight of the dish influence our perception of food? Food Qual Prefer 2011, 22:753-756.

33. Piqueras-Fiszman B, Spence C: The weight of the container influences expected satiety, perceived density, and subsequent expected fullness. Appetite 2012, 58:559-562.

34. Spence C, Piqueras-Fiszman B: Multisensory design: weight and multisensory product perception. In Proceedings of RightWeight2. Edited by Hollington G. London: Materials KTN; 2011:8-18.

35. Brunstrom JM, Rogers PJ, Burn JF, Collingwood JM, Maynard OM, Brown SD, Sell NR: Expected satiety influences actual satiety. Appetite 2010, 54:637.

36. Brunstrom JM, Wilkinson LL: Conditioning expectations about the satiating quality of food. Appetite 2007, 49:281.

37. Piqueras-Fiszman B, Spence C: The influence of the feel of product packaging on the perception of the oral-somatosensory texture of food. Food Qual Prefer 2012, 26:67-73. 
38. Williams LE, Bargh JA: Experiencing physical warmth promotes interpersonal warmth. Science 2008, 322:606-607.

39. Piqueras-Fiszman B, Spence C: The influence of the color of the cup on consumers' perception of a hot beverage. J Sensory Stud 2012, 27:324-331.

40. Peck J, Childers TL: Individual differences in haptic information processing: the "Need for Touch" scale. J Consumer Res 2003, 30:430-442

41. Peck J, Childers TL: To have and to hold: the influence of haptic information on product judgments. J Marketing 2003, 67:35-48.

42. Peck J, Johnson JW: Autotelic need for touch, haptics, and persuasion: the role of involvement. Psychol Marketing 2011, 28:222-239.

43. Workman JE: Fashion consumer groups, gender, and need for touch. Cloth Text Res J 2010, 28:126-139.

44. Harrar V, Spence C: A weighty matter: the effect of spoon size and weight on food perception. Seeing Perceiving 2012, 25(Suppl):199.

45. Howes P, Wongsriruksa S, Laughlin Z, Witchel HJ, Miodownik M: The perception of materials through oral sensation. 2012, unpublished manuscript.

46. Piqueras-Fiszman B, Laughlin Z, Miodownik M, Spence C: Tasting spoons: assessing how the material of a spoon affects the taste of the food. Food Qual Prefer 2012, 24:24-29.

47. Crumpacker B: The Sex Life of Food: When Body and Soul Meet to Eat. New York: Thomas Dunne Books; 2006.

48. Martel Y: Life of Pi. New York: Harcourt Trade Publishers; 2001

49. The polite way to eat with your fingers, by Debrett's. The Daily Mail. 2012, 9. http://www.telegraph.co.uk/foodanddrink/foodanddrinknews/9696223/ How-to-eat-with-ones-fingers-the-Debretts-guide-to-very-modernetiquette. html.

50. Pelaccio Z: Eat with Your Hands. New York: Ecco; 2012.

51. Alinea Restaurant. https://www.alinearestaurant.com.

52. II Giambellino. http://www.lgiambellino.it

53. Barnett-Cowan M: An illusion you can sink your teeth into: haptic cues modulate the perceived freshness and crispness of pretzels. Perception 2010, 39:1684-1686.

54. Szczesniak AS: Psychorheology and texture as factors controlling consumer acceptance of food. Cereal Foods World 1990, 351:1201-1205.

55. Szczesniak AS, Kahn EL: Consumer awareness of and attitudes to food texture I: adults. J Texture Stud 1971, 2:280-295.

56. Szczesniak AS, Kleyn DH: Consumer awareness of texture and other food attributes. Food Technol 1963, 17:74-77.

57. Green BG, Lawless HT: The psychophysics of somatosensory chemoreception in the nose and mouth. In Smell and Taste in Health and Disease. Edited by Getchell TV, Doty RL, Bartoshuk LM, Snow JB. New York: Raven Press; 1991:235-253.

58. Stevenson RJ: The Psychology of Flavour. Oxford: Oxford University Press; 2009.

59. Bourne MC: Food Texture and Viscosity. New York: Academic Press; 1982.

60. Delwiche JF: Attributes believed to impact flavor: an opinion survey. J Sens Stud 2003, 18:437-444

61. Spence C, Smith B, Auvray M: Confusing tastes and flavours. In The Senses. Edited by Matthen M, Stokes D. Oxford: Oxford University Press; in press.

62. Chandrashekar J, Yarmolinsky D, von Buchholtz L, Oka Y, Sly W, Ryba NJP, Zuker CS: The taste of carbonation. Science 2009, 326:443-445.

63. Bult JHF, de Wijk RA, Hummel T: Investigations on multimodal sensory integration: texture, taste, and ortho- and retronasal olfactory stimuli in concert. Neurosci Lett 2007, 411:6-10.

64. Mattes RD: Is there a fatty acid taste? Annu Rev Nutr 2009, 29:305-327.

65. Breslin PAS, Gilmore MM, Beauchamp GK, Green BG: Psychophysical evidence that oral astringency is a tactile sensation. Chem Senses 1993, 18:405-417.

66. Christensen CM: Food texture perception. In Advances in Food Research. Edited by Mark E. New York: Academic Press; 1984:199.

67. Gawel R, Oberholster A, Francis IL: A 'Mouth-feel Wheel': terminology for communicating the mouth-feel characteristics of red wine. Australian Society of Viticulture and Oenology 2000, 6:203-207.

68. Kappes SM, Schmidt SJ, Lee S-Y: Relationship between physical properties and sensory attributes of carbonated beverages. J Food Science 2007, 72:S001-S011.

69. Langstaff SA, Guinard J-X, Lewis MJ: Sensory evaluation of the mouthfeel of beer. Am Soc of Brewing Chemists 1991, 49:54-59.

70. Marsili R: Texture and mouthfeel making rheology real. Food Prod Design 1993, 8:54-58.
71. Szczesniak AS: Classification of mouthfeel characteristics of beverages. In Food Texture and Rheology. Edited by Sherman P. London: Academic Press; 1979

72. Jowitt R: The terminology of food texture. J Texture Stud 1974, 5:351-358.

73. Frost MB, Janhoj T: Understanding creaminess. Int Dairy J 2007, 17:1298-1311.

74. Weel KGC, Boelrijk AC, Alting PJJM, van Mil JJ, Burger H, Gruppen $H_{\text {, }}$ Voragen AGJ, Smit G: Flavor release and perception of flavored whey protein gels: perception is determined by texture rather than by release. J Agr Food Chem 2002, 50:5149-5155.

75. Christensen CM: Effects of solution viscosity on perceived saltiness and sweetness. Percept Psychophys 1980, 28:347-353.

76. Delwiche J: The impact of perceptual interactions on perceived flavor. Food Qual Prefer 2004, 15:137-146.

77. Kutter A, Hanesch C, Rauh C, Delgado A: Impact of proprioception and tactile sensations in the mouth on the perceived thickness of semi-solid food. Food Qual Prefer 2011, 22:193-197.

78. Sundqvist NC, Stevenson RJ, Bishop IRJ: Can odours acquire fat-like properties? Appetite 2006, 47:91-99.

79. Tournier C, Sulmont-Rossé C, Sémon E, Vignon A, Issanchou S, Guichard E: A study on texture-taste-aroma interactions: physico-chemical and cognitive mechanisms. Int Dairy J 2009, 19:450-458.

80. Green BG: Studying taste as a cutaneous sense. Food Qual Prefer 2002, 14:99-109.

81. Lim J, Green BG: Tactile interaction with taste localization: influence of gustatory quality and intensity. Chem Senses 2008, 33:137-143.

82. Todrank J, Bartoshuk LM: A taste illusion: taste sensation localized by touch. Physiol Behav 1991, 50:1027-1031.

83. Stevenson RJ: The role of attention in flavour perception. Flavour 2012, 1:2.

84. Murphy C, Cain WS: Taste and olfaction: independence vs. interaction. Physiol Behav 1980, 24:601-605

85. Alais $D$, Burr $D$ : The ventriloquist effect results from near-optimal bimodal integration. Curr Biol 2004, 14:257-262.

86. Lim J, Johnson MB: Potential mechanisms of retronasal odor referral to the mouth. Chem Senses 2011, 36:283-289.

87. Lim J, Johnson M: The role of congruency in retronasal odor referral to the mouth. Chem Senses 2012, 37:515-521.

88. Cruz A, Green BG: Thermal stimulation of taste. Nature 2000, 403:889-892

89. Green BG, George P: 'Thermal taste' predicts higher responsiveness to chemical taste and flavor. Chem Senses 2004, 29:617-628.

90. Simon SA, de Araujo IE, Gutierrez R, Nicolelis MAL: The neural mechanisms of gustation: a distributed processing code. Nat Rev Neurosci 2006, 7:890-901

91. Cerf-Ducastel B, Van de Moortele P-F, Macleod P, Le Bihan D, Faurion A: Interaction of gustatory and lingual somatosensory perceptions at the cortical level in the human: a functional magnetic resonance imaging study. Chem Senses 2001, 26:371-383.

92. Eldeghaidy S, Marciani L, McGlone F, Hollowood T, Hort J, Head K, Taylor AJ, Busch J, Spiller RC, Gowland PA, Francis ST: The cortical response to the oral perception of fat emulsions and the effect of taster status. J Neurophysiol 2001, 105:2572-2581.

93. De Araujo IE, Rolls ET: Representation in the human brain of food texture and oral fat. J Neurosci 2004, 24:3086-3093.

94. Prescott J: Taste Matters: Why We Like the Foods We Do. London: Reaktion Books; 2012

95. Munoz AM, Civille GV: Factors affecting perception and acceptance of food texture by American consumers. Food Reviews International 1987, 3:285-322.

96. Guinard J-X, Mazzucchelli R: The sensory perception of texture and mouthfeel. Trends Food Sci Technol 1996, 7:213-219.

97. Szczesniak AS: Texture is a sensory property. Food Qual Prefer 2002, $13: 215-225$.

98. Szczesniak AS, Kahn EL: Texture contrasts and combinations: a valued consumer attribute. J Texture Stud 1984, 15:285-301.

99. Spence C, Piqueras-Fiszman B: Dining in the dark: why, exactly, is the experience so popular? The Psychologist 2012, 25:888-891.

100. Marije Vogelzang: www.marijevogelzang.nl.

101. Masuda M, Yamaguchi Y, Arai K, Okajima K: Effect of auditory information on food recognition. IEICE Tech Rep 2008, 108:123-126.

102. Spence C: Auditory contributions to flavour perception and feeding behaviour. Physiol Behav 2012, 107:505-515 
103. Zampini M, Spence C: The role of auditory cues in modulating the perceived crispness and staleness of potato chips. J Sens Sci 2004, 19:347-363

104. Spence C, Shankar MU, Blumenthal H: 'Sound bites': auditory contributions to the perception and consumption of food and drink. In Art and the Senses. Edited by Bacci F, Mecher D. Oxford: Oxford University Press; 2011:207-238.

105. Zampini M, Spence C: Modifying the multisensory perception of a carbonated beverage using auditory cues. Food Qual Prefer 2005, 16:632-641.

106. Spence C: Multi-sensory integration \& the psychophysics of flavour perception. In Food Oral Processing - Fundamentals of Eating and Sensory Perception. Edited by Chen J, Engelen L. Oxford: Blackwell Publishing; 2012:203-219.

107. Bolanowski SJ, Verrillo RT, McGlone F: Passive, active and intra-active (self) touch. Somatosens Mot Res 1999, 16:304-311.

108. Crusco AH, Wetzel CG: The Midas touch: the effects of interpersonal touch on restaurant tipping. Pers Soc Psychol Bull 1984, 10:512-517.

109. Stephen R, Zweigenhaft RL: The effect on tipping of a waitress touching male and female customers. J Soc Psychol 1986, 126:141-142.

110. Guéguen N, Jacob C: The effect of touch on tipping: an evaluation in a French bar. Hospitality Manage 2005, 24:295-299.

111. Kaufman D, Mahoney JM: The effect of waitresses' touch on alcohol consumption in dyads. J Soc Psychol 1999, 139:261-267.

112. Guéguen N, Jacob C, Boulbry G: The effect of touch on compliance with a restaurant's employee suggestion. Hospitality Manage 2007, 26:1019-1023.

113. Eaton M, Mitchell-Bonair I, Friedmann E: The effect of touch on nutritional intake of chronic organic brain syndrome patients. J Gerontol 1986, 41:611-616.

114. Gallace A, Spence C: The science of interpersonal touch: an overview. Neurosci Biobehav Rev 2010, 34:246-259.

115. Madeleines Madteater: http://www.madeleines.dk.

116. Piqueras-Fiszman B, Spence C: Sensory incongruity in the food and beverage sector: art, science, and commercialization. Petits Propos Culinaires 2012, 95:74-118.

117. Hashimoto Y, Nagaya N, Kojima M, Miyajima S, Ohtaki J, Yamamoto A, Mitani T, Inami M: Straw-like user interface: virtual experience of the sensation of drinking using a straw. In Proceedings World Haptics 2007. Edited by. Los Alamitos, CA: IEEE Computer Society; 2007:557-558.

118. Hashimoto Y, Inami M, Kajimoto H: Straw-like user interface (II): a new method of presenting auditory sensations for a more natural experience. In Eurohaptics 2008, LNCS, 5024. Edited by Ferre M. Berlin: Springer-Verlag; 2008:484-493.

119. Grimes A, Harper R: Celebratory technology: new directions for food research in $\mathrm{HCl}$. In Proceedings of the $26^{\text {th }}$ Annual SIGCHI Conference on Human Factors in Computing Systems 2008 (CHI'08). Edited by. New York: ACM; 2008:467-476.

120. Salen K, Zimmerman E: Rules of play. Boston: MIT Press; 2003.

121. Philips Design Probe: http://www.design.philips.com/philips/sites/ philipsdesign/about/design/designportfolio/design_futures/food.page.

122. Toet $E$, Meerbeek B, Hoonhout J: Supporting mindful eating with the InBalance chopping board. In Eat, Cook, Grow: Mixing Human-Computer Interactions with Human-Food Interactions. Edited by Choi JH-J, Foth M, Hearn G. Cambridge, MA: MIT Press; in press.

123. Spence C, Piqueras-Fiszman B: Technology at the dining table. Flavour, in press.

124. Stones M: More lightweighting needed to cut packaging waste, says watch dog. http://www.foodproductiondaily.com/Packaging/Morelightweighting-needed-to-cut-packaging-waste-says-UK-watch-dog.

125. ISO: Standard 5492: Terms relating to sensory analysis. International Organization for Standardization; 1992.

126. ISO: Standard 5492: Terms relating to sensory analysis. International Organization for Standardization; 2008.

doi:10.1186/2044-7248-2-14

Cite this article as: Spence et al:: A touch of gastronomy. Flavour 2013 2:14

\section{Submit your next manuscript to BioMed Central and take full advantage of:}

- Convenient online submission

- Thorough peer review

- No space constraints or color figure charges

- Immediate publication on acceptance

- Inclusion in PubMed, CAS, Scopus and Google Scholar

- Research which is freely available for redistribution 